This item was submitted to Loughborough's Institutional Repository (https://dspace.lboro.ac.uk/) by the author and is made available under the following Creative Commons Licence conditions.

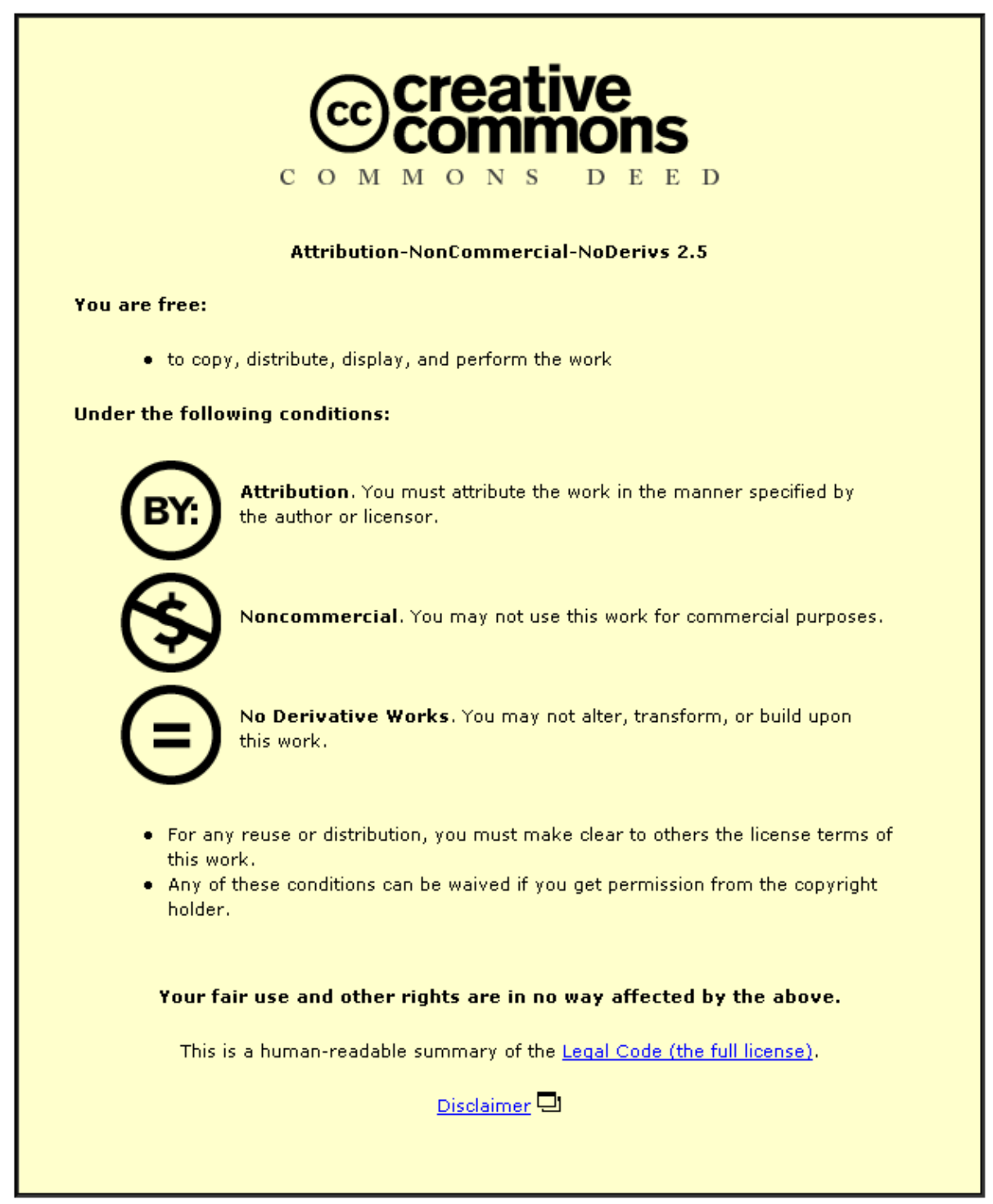

For the full text of this licence, please go to: http://creativecommons.org/licenses/by-nc-nd/2.5/ 
Medicine

Elsevier Editorial system(tm) for Social Science \& Manuscript Draft

Manuscript Number: SSM-D-07-01159R3

Title: Imperial or postcolonial governance: dissecting the genealogy of a global public health strategy

Article Type: Article

Section/Category: Medical Geography

Keywords: WHO, global public health, non-communicable diseases, imperialism, postcolonialism

Corresponding Author: Dr Tim Brown, PhD

Corresponding Author's Institution: Queen Mary, University of London

First Author: Tim Brown, PhD

Order of Authors: Tim Brown, PhD; Morag Bell, PhD

Manuscript Region of Origin: UNITED KINGDOM 


\title{
Imperial or postcolonial governance: dissecting the genealogy of a global public health strategy
}

\begin{abstract}
During the last decades of the twentieth century it became increasingly apparent that the inter-relationship between globalisation and health is extremely complex. This complexity is highlighted in debates surrounding the re-emergence of infectious diseases, where it is recognised that the processes of globalisation have combined to create the conditions where once localised, microbial hazards have come to pose a threat to many western nations. By contrast, in an emerging literature relating to the epidemic of non-communicable diseases, and reflected in the WHO 'Global strategy on diet, physical activity and health', it is the so-called 'western lifestyle' that has been cast as the main threat to a population's health. This paper explores critically global responses to this development. Building on our interest in questions of governance and the ethical management of the healthy body, we examine, whether the global strategy, in seeking to contain the influence of a 'western lifestyle', also promotes contemporary 'western-inspired' approaches to public health practices. The paper indicates that a partial reading of the WHO strategy suggests that certain countries, especially those outside the West, are being captured or 'enframed' by the integrative ambitions of a western 'imperial' vision of global health. However, when interpreted critically through a post-colonial lens, we argue that 'integration' is more complex, and that the subtle and dynamic relations of power that exist between countries of the West/non-West, are exposed.
\end{abstract}

\section{Introduction}

On May 22, 2004 the 192-member World Health Assembly, the main decisionmaking body of the World Health Organization (WHO), endorsed a 'Global strategy on diet, physical activity and health'. As Dr Lee Jong-wook, the DirectorGeneral of WHO, announced, "This is a landmark achievement in global public health policy" (WHO, 2004. Emphasis added). Such a reference to the global reach of the strategy is significant as it appears to endorse further the idea that the 'global' has replaced the 'national' in public health discourse. Indeed, the belief that public health has transcended national borders and boundaries is reflected in the current literature. Much of this literature can be organised into three distinct areas: the history of the transformation from national to global public health (see Loughlin and Berridge, 2002; Bashford, 2006; Brown, Cueto and Fee, 2006); the links between globalisation and the (re)emergence of infectious diseases in the West (see Garrett, 1995, 1996; Heymann and Rodier, 2001; Ali and Keil, 2006); and, the association between westernisation and the global transfer of risks factors for so-called 'diseases of comfort' (see Yach and Bettcher, 1998; McMichael and Beaglehole, 2000; Beaglehole and Yach, 2003).

This globalising of public health discourse was the focus of previous research by the authors (see Brown and Bell, 2007). In this work we argued that the WHO 
global strategy provided opportunities for western forms of public health knowledge and practice, especially those relating to the regulation and management of the sedentary body, to be translated into national contexts outside of the West. In examining this proposition, we referred to the ways in which the natural environment has, in many western countries at least, been appropriated as a site within which individuals are increasingly encouraged to perform techniques of self-care: particularly, though not exclusively, "healthy walking'. We then examined whether this particular form of pre-emptive public health had travelled beyond the West. We concluded that although there was only limited evidence of the (re)medicalisation of nature, the somatic discourse associated with the so-called 'new' public health had indeed become a global rather than simply a western phenomenon (cf. Lupton, 1995; Petersen and Lupton, 1996).

A key objective of the WHO global strategy is, then, to inform, and even shape, the decisions that populations make with regards to their everyday health-related choices and responsibilities. Put differently, it could be argued that the strategy promotes an 'ethics of care' (see Rose, 1999), as it seems reasonable to assume that, as western lifestyle and consumption patterns travel across the globe, so too will the forms of ethico-politics through which populations are encouraged to regulate their behaviour and govern their bodies. Though we would argue that this remains an important line of inquiry, we adopt a very different analytical perspective in the paper that we present here. More specifically, we examine in detail the genealogy of the global strategy. In this sense, we are interested in the lines of descent and lineage of the global strategy and seek to trace these through to the contemporary period. We do so because we are concerned to explore its 'integrative' qualities and to analyse critically the processes, interactions and debates through which it came into being. In order to do so, we adopt a post-colonial position.

Undoubtedly there has been a sustained engagement with postcolonialism by geographers and others (McEwan 2003); within these accounts, the term has been used in a variety of ways and has rarely "lent itself to consensual definition" (Slater 1998: 652). For example, the term 'postcolonial' has been employed to describe a condition, the period after colonialism and to signify a set of critical perspectives committed to exposing, deconstructing and countering the "cultural and broader ideological legacies and presences of imperialism" (Sidaway, 2000: 594). This paper is not concerned with the former of these; nor does it focus on the cultural and ideological legacies of imperialism, if this refers to the ways in which colonial power was diffused through, structured and framed social relations both within the centre(s) and on the edge(s) of empire. Nevertheless, contemporary debates about global health are shaped by the persistence of what Chakrabarty (1992) has termed a colonial 'transition narrative' whose assumed endpoint is the development and modernisation of non-western states. It is upon this feature of the global strategy that we focus, identifying both the presence of 
this 'transition' narrative in the discourse surrounding the strategy and, as importantly, the emergence of challenges to it from outside of the West.

According to King, this 'transition narrative' is an important feature of contemporary discourse surrounding the emerging and re-emerging infectious diseases debate. As he notes, where imperial public health was concerned with the "conversion" of indigenous medicine, the postcolonial agenda has "integration as its goal and its dominant metaphor" (2002: 782). As our analysis reveals, such a reading can be applied to the WHO global strategy whose aim is to integrate non-western nations into a global public health regime. However, there is one aspect of King's reading that we find less satisfying. Specifically it raises concerns, similar to those levelled at neo-colonialism, regarding the power of the imperial centre and the passivity of the periphery; as Slater argues, "neocolonialism overplays the power of imperial centres and enframes the Third World as passive and continually captured" (1998: 654).

In our view this description of postcolonial global public health appears to position the countries of the non-West within a (post)imperial 'will to power' (Said 1978). Put differently, there are silences in King's interpretation that imply the projection of western knowledge and power overseas. As Driver argues, we need to rethink this relationship and view the non-western world, not as a screen, but as a "living space of encounter and exchange" (2004: 3-4). Thus, although many of the ideas positioned in the global strategy might appear to have a particular point of origin (Brown and Bell, 2007), we are aware that the global diffusion of public health knowledge and practice is not a one-way flow. To this end, in this paper we go on to identify resistances to the global strategy and we refer to sources of public health knowledge and practice that provide a counter to "dominant western-based conceptualizations" (Slater, 1998: 662).

The starting point for such an analysis was the discourse surrounding the publication of the global strategy in 2004: including documentation produced by the World Health Assembly, the speeches that were made upon the strategy's unveiling and the newspaper media coverage of it. Yet, as we state, we are concerned in this paper with the genealogy of this strategy and with identifying possible resistances to it. In order to achieve these aims we draw upon a much broader array of textual resources. For example, we traced the emergence of the strategy, its genealogy, through the archives of the WHO. More specifically, we followed the trail of the strategy through the Health Assembly and Executive Board records using the on-line WHO documentation archive and we collated material that was used to support the case for it: including relevant research reports, policy documents, health-related reports and speeches. Once collated, this material was positioned within a time-line, which, as we reveal below, can be traced back at least to the mid-1960s.

Clearly, such a plethora of material has the potential to reveal many themes. However, as we have already suggested, we were especially concerned to 
explore the justification for the global strategy and the arguments that were made for extending it to the non-West. In this sense, then, we were able to focus specific attention on documents, or passages within documents, that referred to these aspects of the strategy. What follows in the following sections are the results of this endeavour. What we provide is a critical reading of this material rather than a detailed description of it. Indeed, the analytical approach adopted is interpretive, drawing implicitly on Foucaultian discourse analysis (on which see Mills, 1997). As such, we view discourse not only as a group of signs but as practices that play a major role in the constitution of social subjectivity. To this end, we identify how the discursive structures operating within, and through, the discussion of the strategy, whether in policy documents, speeches or newspaper reports, help to shape understanding of those 'enframed' within it.

\section{Situating the global strategy}

If we trace the genealogy of the WHO global strategy through the archives of the World Health Assembly it is possible to identify a series of resolutions that have, in some way or other, informed its development. For example, in 1966, 1972 and again in 1976, the assembly requested that WHO explore the possibility of expanding programmes relating to the prevention and control of cardiovascular diseases (WHO, 1966, 1972, 1976). Furthermore, in 1985, this concern was extended as the assembly, the main decision-making body for WHO, called upon member states to assess the national importance of all non-communicable diseases, to develop population-centred measures for their prevention and control and, where appropriate, to exchange this knowledge and understanding with other nations. As the resolution stated, this was necessary because noncommunicable diseases were recognised as "major factors adversely affecting life expectancy and health in general in both developed and developing countries" (WHO, 1985. Emphasis added).

Though such concern implies that a growing sense of urgency surrounded the issue of non-communicable diseases, the period leading up to the unveiling of the WHO strategy in 2004 was, in reality, marked by the gradual collation of evidence rather than the establishing of a global intervention programme (Bauman and Craig, 2005). In the following sections, we provide a comprehensive reading of this evidence because we believe it is fundamental to developing an understanding of the global strategy. As might be anticipated from our introduction, this reading is informed by Foucauldian approaches to discourse analysis (Foucault, 1977). However, we are also influenced by King's (2002) notion of the 'worldview' because, similarly to Foucault, it highlights the ways in which discourse acts to shape a discursive field and, in so doing, to limit one's 'field of vision'. As we go on to argue, this was an important element of the global strategy because it helped to integrate or 'enframe' nations not normally linked to health-related problems associated with non-communicable diseases.

Framing the debate 
In March, 1989 a small group of international scientists met at the WHO headquarters in Geneva to provide recommendations on limiting the global impact of non-communicable diseases. The scientists, many of whom were from non-western countries, were joined by experts from other international organisations and by members of the WHO secretariat. The outcome of this meeting, a WHO Technical Series Report entitled Diet, nutrition and the prevention of chronic diseases (WHO, 1990), is significant because it represents a key moment in the development of the global strategy some 15 years later. Indeed, many of the central features of this report are reflected in it: for example, it identified worldwide changes in dietary habits and physical activity levels, the influence of industrialisation, urbanisation, economic development and the food industry on these changes in behaviour and the subsequent rise in noncommunicable diseases, which now represent some $47 \%$ of the global disease burden (WHO, 2004a).

Though of broader significance, it is our intention to consider those aspects of this report that are of most relevance to the argument(s) presented here. In particular, we focus our attention on three themes that are central to the framing of subsequent global debate: the health transition, the respatialisation of noncommunicable diseases and ideas about population, risk and governance. Beginning with the former, it is important to note that the concept, as imagined in the report, relies on Omran's notion of the epidemiological transition (see Omran, 1971). As the report states, "after reviewing the descriptive epidemiological data from many developing and developed countries, [it has been] concluded that there is usually a sequence in the emergence of chronic disease..." (WHO, 1990: 34. Emphasis added). Though only a very subtle allusion to the epidemiologic transition, this reference to the sequential way in which non-communicable diseases emerge as societies progress is important because it imagines a similar teleology to that found in Omran's original conceptualisation.

In order to sustain this teleology, the report relies on the authority of the evidence used to support it; most notably, that which relates to the experience of certain 'traditional' societies undergoing "rapid transition between cultural stages" (1990: 27). For example, it was noted that changes to the dietary habits and physical activity patterns of aboriginal or first nation peoples in Australia, the United States and certain South Pacific islands had resulted in higher rates of obesity, diabetes, hypertension and coronary heart disease. The island of Mauritius, which saw its death rates from cardiovascular diseases increase from $2 \%$ in the 1940 s to $45 \%$ in the 1980 s, was also employed in the defence of this argument because it was "frequently cited as an example of a country in which economic and social transition has occurred unusually rapidly" (WHO, 1990: 36). Thus, despite considerable criticism (see Seale, 2000), the principles upon which the epidemiological transition are based remain and the concept continues to be used as if it "constituted a theory of general validity" (Carolina and Gustavo, 2003: 541. Emphasis in original). 
The relevance of this to our argument is that it implies a continuation of the modernisation paradigm, which is based "on a dichotomous view of 'modern' and 'traditional' societies, or West and non-West" (Slater, 1993: 421). In the case of this report, what appear to be carefully selected examples of such 'traditional' societies have been mobilised to explain what happens to health when the rapid modernisation of economic, social and cultural life occurs. Clearly this is a problematic viewpoint. As Carolina and Gustavo (2003: 540) argue, one issue is that the "illusory certainty of a predetermined destiny" actually distorts our understanding of what is taking place within individual nations. However, of equal interest is the notion that we can see within this argument a subtle redefining of the modernisation thesis. Indeed, rather than learning from and mirroring the West, so-called 'traditional' societies are encouraged to observe the dangers that the globalising of western practices brings. In this sense, the western 'way of life' does not emerge in this discourse as a sign of progress; rather, it emerges as a signifier of future ill-health.

This leads us to a second theme, the respatialisation of non-communicable diseases. At the time of the report's publication, such diseases were still imagined to exist pre-dominantly in the West; they were invariably defined as being a result of the "'affluent" diet that prevailed in many developed countries" (WHO, 1990: 9). While this was the case, the report also sought to highlight the growing concern surrounding certain areas of the non-western world where the threat of non-communicable diseases was emerging: "[r]apid changes are occurring in the life-styles and the dietary and health patterns of the populations in developing countries. There has been a huge increase in the numbers of people moving from rural to urban communities, where striking changes in diet often occur" (WHO, 1990: 27-8). As this statement implies, the processes of urbanisation, and for that matter of industrialisation, were believed to be creating a social and cultural environment within which indigenous diets had become more "westernized" (WHO, 1990: 34) and according to this narrative inherently more risky.

At the time of the 1989 meeting, it was an urban elite class in non-western countries, rather than urban society per se, that was seen to be most affected. This uneven exposure to the risk factors for non-communicable diseases was argued to result from ideas of cultural differentiation that were attached to the consumption of the so-called 'western' diet: "they [the urban elite class] also perceive the new diet, similar to that of affluent communities, as a symbol of their newly acquired status" (WHO, 1990: 37. Emphasis added). However, we are also reminded that behind such individual desires and cultural aspirations lies the economic power of the global food industry: "[w]ithin the urban setting, the food industry can also flourish and exert substantial influence by promoting the consumption of... convenience foods rich in free sugars and fats". When considered alongside the linearity associated with the epidemiological transition, this representation implies almost irrevocable decline as non-western nations 
modernise and, as a consequence, begin to develop patterns of noncommunicable disease that mirror those found in the West. Again we can see within this representation a subtle inversion of the modernisation paradigm or at least the shadowy figure of degeneration that often lurks behind western ideas of progress (see Pick, 1989).

However, the authors of the report offer some hope: "[d]eveloping countries can benefit by learning from the experience of dietary change and adverse health effects in many developed countries" (WHO, 1990: 13). Moreover, it is suggested that increases in non-communicable diseases are "mediated by the acquisition of certain life-style characteristics" and that "changes in disease pattern are therefore not inevitable" (WHO, 1990: 33). This observation leads us to a third and final theme: population, risk and governance. Our principal concern here is with the scale of analysis used to include 'periphery countries' within a somatic discourse that is normally associated with the industrialised West (Porter, 2000). As noted in the report, the preferred scale of analysis is the population rather than the individual because "[p]ublic health interventions aim to lower the average level of risk to health of whole populations, either because the whole population is at risk, or because a strategy to identify the minority of individuals at greatest risk, even if available, would only contribute to a modest public health improvement..." (WHO, 1990: 12. Emphasis in original).

The question, then, is why the scale of analysis is relevant to our argument. In order to answer this question we refer to a further statement made in the report: "[t]he present Study Group does not consider that [the high-risk individual] approach is an effective way of controlling a problem that is manifest in the population as a whole" (WHO, 1990: 119). This statement establishes the belief that a strategy directed at high-risk individuals or groups would be of little consequence for the governance of non-communicable diseases because "one must see the whole population as potentially at risk" (WHO, 1990: 120). The belief that it was populations rather than individuals that were at risk was made more forcefully a little further on: "the clear conclusion is reached that, in most developing countries, the population is "sick" and the population must be treated" (WHO, 1990: 121. Emphasis added). The significance of this is, in part, related to the idea that the "postcolonial imaginary" involves attempts to integrate periphery countries, here identified as 'developing' countries, into a global circulation of Western knowledge and practice (King, 2002: 783).

Returning to the report once again, we are informed that: "[t]his message has particular importance for the developing countries, since the early signs of the population illness are already becoming apparent" (WHO, 1990: 121). Moreover, it is made apparent that such nations, with the help of WHO, have the opportunity to "ensure that the population never changes its life-style to one where risk factors are evident" (WHO, 1990: 121. Emphasis added). In this sense, all of our themes come together in what King describes, albeit in relation to re-emerging infectious diseases, as a "consistent, self-contained ontology" (2002: 767). Put 
differently, the report established the causes and consequences of the then emerging epidemic in non-communicable diseases, it mapped out current and future patterns of related diseases and it identified the most appropriate methods for preventing and managing this threat to global health. In the following section, we reveal the importance of this 'worldview' to the development of the WHO global strategy before going on to question the extent to which it represents an imperial or post-colonial approach to global health governance.

\section{The authority of risk}

In order to extend our analysis we consider the ongoing development of the global strategy, evidence for which continued to be compiled in the years following the publication of the 1990 report. Indeed, the idea of establishing such a strategy emerged following the publication of two further assessments of the global burden of disease in the mid-1990s (see USDHHS, 1996; WHO, 1997). The latter of these, the World Health Report, 1997, described non-communicable diseases as the "penalty" of progress and pointed, amongst other things, to data suggesting that they cause nearly $40 \%$ of all deaths in 'developing' countries (1997: 20). It was, then, on the basis of evidence such as this that the then Director-General of WHO requested that a global plan for their prevention and control be established. This request was enacted by the 31-member Executive Board of WHO and was subsequently ratified by member states at the $51^{\text {st }}$ session of the world health assembly (WHO, 1998).

Almost inevitably, this commitment to develop a global strategy required WHO to provide evermore clarification of the evidence supporting it. Perhaps this was a necessary tactic to overcome tensions between member states that have been a feature of the organisation almost since its inception (on which see Siddiqi, 1995), particularly as a global strategy on non-communicable diseases might divert resources away from other health-related concerns. Equally plausibly, the decision to enhance the evidence base was linked to the selection of Gro-Harlem Brundtland as the new Director-General in the same year as the strategy's inception. Brundtland had outlined her commitment to the issue in an address delivered to the world health assembly prior to her appointment: "WHO must help governments face the daunting challenge from the new epidemic of noncommunicable diseases" (Brundtland, 1998: 2). As importantly, she went on to state that such an obligation demanded that WHO underpin its work "with solid facts". A successor to the 1990 report, also entitled Diet, Nutrition and the Prevention of Chronic Diseases (WHO/FAO, 2003), provided such facts.

Despite a decade or more having elapsed since the publication of the 1990 report, it is quite apparent that the later document, the WHO/FAO report published in 2003, demonstrates a remarkable consistency in terms of the ways in which arguments for the global strategy were framed. For example, considerable attention was placed on establishing, or perhaps more appropriately, confirming, the link between the processes of modernisation and 
the so-called risk transition: "changes in diets and lifestyles... have occurred with industrialization, urbanization, economic development and market globalization" (WHO/FAO, 2003: 1). Moreover, because non-communicable diseases were considered to be transmissible, due to their being linked to "risk behaviours that travel across countries and are transferable from one population to another like an infectious disease...", their earlier labelling as 'diseases of affluence', or, put differently, as diseases of the West, was thought of as somewhat of a "misnomer" (WHO/FAO, 2003: 4-5. Emphasis added).

Apart from these and other similarities, there are subtle, but important, differences between the 1990 and 2003 reports that are worthy of further analysis. The 1990 report suggests that an opportunity existed for governments, particularly those of countries located in the developing world, to resist the threat of non-communicable diseases. Yet, as the $2003 \mathrm{WHO} / \mathrm{FAO}$ report states, by the turn of the $21^{\text {st }}$ century this opportunity had apparently been lost because of the pace at which change had occurred: "Rapid changes in diets and lifestyles... have accelerated over the past decade" (WHO/FAO, 2003: 1); "the shift in the pattern of disease is taking place at an accelerating rate" (WHO/FAO, 2003: 4). In addition, the concern to prevent the westernisation of 'traditional' lifestyles had all but disappeared as the evidence contained within the report suggested that such a transformation had already taken place: "great changes have swept the entire world since the second half of the twentieth century, inducing major modifications in diet, first in industrial regions and more recently in developing countries" (WHO/FAO, 2003: 6).

Perhaps more importantly, however, the WHO/FAO report places a greater emphasis on the notion of risk. We are not suggesting that the notion of risk was absent in earlier reports, including the 1990 report. That said, a close reading of the follow-up report reveals that the explicatory power, or even authority, of this concept was given greater prominence than before. Indeed, it is apparent that there is less reliance on, what might be regarded as, overly descriptive accounts of the epidemiological or health transition as it takes place within individual nations or amongst groups of indigenous peoples and more focus on the connection between risk factors and health outcomes. As stated in the report, "[t]his report calls for a shift in the conceptual framework for developing strategies for action, placing... [the] principal risk factors for chronic disease - at the forefront of public health policies and programmes" (WHO/FAO, 2003: 3). The question, of course, is why this subtle shift in the framing of the public health response to non-communicable diseases is relevant to the arguments that we develop in this paper.

The answer to this question was alluded to in a slightly earlier, but equally significant, report, the World Health Report, 2002, in which it was stated that the health transition is usually understood in terms of the "patterns of disease" associated with it rather than in relation to the "risk factors that shape" these patterns (WHO, 2002: 84. Emphasis added). This observation is important for 
two reasons. Firstly, the focus on contemporary patterns of risk, rather than on patterns of non-communicable diseases, appears to be regarded as a more effective mechanism for encouraging nations, particularly those outside of the industrialised West, to recognise that non-communicable diseases are threats to health that exist in the present and not only in the future. Such a manoeuvre not only involved redefining the boundaries of risk, it also involved identifying the 'developing world' as the region within which the greatest global burden of such risk exists: "for risks, traditionally thought to be "Western", such as elevated body mass or cholesterol, more burden now occurs in developing than developed countries" (WHO, 2002: 84).

Secondly, the identification of the risks for non-communicable diseases as a world-wide, rather than a regional, threat is important because it provides a more authoritative evidential basis upon which to incorporate so-called 'periphery countries' into the subsequent global strategy. As the World Health Report, 2002 states, "[t]he fact is that so-called "Western" risks no longer exist as such. There are only global risks, and risks faced by developing countries" (WHO, 2002: 5). Although the significance of other public health-related problems was acknowledged, there is also a sense in which the later reports seek to cajole 'developing countries' into taking more concrete action against the risks associated with non-communicable diseases. As stated in the WHO/FAO report, "The need for action to strengthen control and prevention measures to counter the spread of the chronic disease epidemic is now widely recognized by many countries, but the developing countries are lagging behind in implementing such measures" (2003: 6. Emphasis added).

\section{A post-colonial strategy?}

Thus far, we have sought to explore the ways in which a particular vision of global health was mobilised within the evidence supporting the WHO global strategy. As would be anticipated, this vision was reproduced and sustained within the rhetoric of the 16-page strategy document itself. For instance, we are informed that "[a] profound shift in the balance of the major causes of death and disease has already occurred in developed countries and is under way in many developing countries", that "the burden of mortality, morbidity and disability attributable to noncommunicable diseases is currently greatest and continuing to grow in the developing countries" and that because the risk factors for such diseases are "largely the same" in all parts of the world so too are the solutions (WHO, 2004a). It is at this point in the paper that we might turn to the 'enframing' of the non-western nations in a global 'ethics of care'. However, if we read the strategy as a process we are able to uncover moments in what might be regarded as a post-colonial dialogue.

In the remainder of this paper, then, we seek to identify those spaces within which ideas and practices, here related to non-communicable diseases and their global management, are accommodated and transformed as they travel from one 
context to another (see Said, 1983: 226ff). In so doing, we question whether or not the global strategy might be regarded as a "postcolonial device" (Bell, 2002); one in which the de-centred and fluid nature of relations between the countries of the North and South are exposed. In order to achieve these ambitions, we shift our attention to the consultation process established by WHO, which sought to refine and agree the final text of the global strategy through discussions with a variety of stakeholders, including: member states, UN agencies and nongovernmental organisations, civil society and the private sector. The response of the member states was initially captured in reports on each of six regional consultation meetings that took place between March and June, 2003. These meetings, which were attended by less than half of the nations that constitute the world health assembly, appear to have been carefully choreographed. Each member state received a consultation document prior to the event that identified "the problem", provided recommendations regarding "the solution" and proposed an institutional mechanism for putting "science into action" (WHO, 2003a). Moreover, the meetings were orchestrated by representatives of the various regional offices and by members of the WHO Secretariat.

Such close management might be interpreted as a mechanism for framing the discussion of, and response to, the WHO global strategy. However, if we examine the consultation process a little more carefully it is apparent that such a reading undermines the role that many nations, including non-western ones, played in shaping the text of the twenty-two page document that finally appeared in May 2004. This role was not always active, as many nations declined the opportunity to be involved. Though we cannot be certain, such an act could be regarded as a political gesture that signalled a rejection of the global strategy; particularly because the decision to be absent, rather than present, during the various stages of the process was often taken by countries whose main public health concerns appear far removed from the rhetoric that underpins it. Yet, for those nations that did take part, the consultation process provided a space within which they could influence what might otherwise be regarded as an implicitly western vision of global health.

For instance, national representatives were encouraged to identify "the levels and trends" of non-communicable diseases in their countries (WHO, 2003a: 3). Of course, many did. However, others used this request as an opportunity to locate the threat posed by such diseases within a much broader national context: "HIVIAIDS and other sexually transmitted diseases are the major public health concerns in Cameroon" and "In Kenya some $55 \%$ of the population live below the poverty line. Rainfall is unreliable, often resulting in poor harvests and low yields. Communicable diseases such as malaria are the leading causes of death, and surveillance focuses on these diseases" (WHO, 2003b: 11-12). Further, the countries comprising the African region also stated, following their regional consultation meeting, that it was important for the global strategy to be built on epidemiological data which did not come from western countries but was 
"relevant to developing countries where diets and other factors may differ substantially" (2003b: 9).

These kinds of interventions were mirrored in the responses that individual countries made to a draft version of the global strategy. India, for example, stated that more emphasis needed to be placed on the "incidence of diseases stemming from malnutrition and problems of poverty and hunger" and South Africa, perhaps for obvious reasons, noted that "[m]ember states should recognize that the burden of NCDs... has been subjugated by the HIV and AIDS pandemic" (for details see WHO, 2004c). In another intervention, Mauritius, a country that was cited as an example where rapid modernisation had had a devastating effect on the population's health, questioned what it believed to be an important failing at the heart of the strategy; its flawed evidence base and the fact that it promoted a "'"one size fits all"' solution. Indeed, drawing on the text of an earlier meeting between the Group of 77 countries and China, WHO and the FAO, the representative for Mauritius pointed to the fact that this influential UN body was concerned that the global strategy overlooked the fact that "every society practices a range of diets and each diet is, in turn, a reflection of specific social preferences".

Clearly, the cultural and social significance of food that is reflected in this last statement represents a considerable challenge to the ambitions of the WHO global strategy. This is particularly so because the G77 and China is the largest intergovernmental organization of 'developing' states in the UN and its aim is to provide a forum through which the countries of the South "articulate and promote" their collective interests and "enhance their joint negotiating capacity" (http://www.g77.org/doc/. Accessed 29 May 2008). Yet, the countries highlighting these concerns were not necessarily employing the idea of cultural difference as a means to frustrate these ambitions. Rather, they referred to such difference as a means to open up space for negotiation and to ensure that the strategy, in the words of the African region, is not solely based on evidence from "western countries" and "reflects the realities faced by countries, recognizes regional, national and local differences, [and] is sensitive to cultural aspects" (2003b: 18). The point we are making here is that many countries, though willing to accommodate the global strategy, sought to transform it into a form of public health intervention that was more applicable to their particular national contexts. On this basis, it appears difficult to sustain the view that the strategy represents merely an imperial approach to public health that attempts to integrate periphery countries into a largely western vision of global health governance.

Indeed, it is worth noting that, although many of the countries of the North were particularly influential in shaping the final text of the document, it was a short intervention by the $\mathrm{G} 77$ and China that was responsible for its near derailment. In a letter sent to the Director-General of WHO on 27 February 2004, this intergovernmental organisation for developing countries stated that "[d]ue to concerns relating to substantive aspects of the draft strategy" the G77 and China 
considered it necessary to hold "further and in-depth consultations with relevant stakeholders". The exact nature of the discussions that took place is difficult to ascertain, although a brief statement posted on the organisation's website indicates that their support came with certain conditions. More specifically, that the global strategy was "scientifically based, supportive of a better balance in total energy intake, undamaging to national food security, economically affordable, sensitive to cultural heritage and in accordance with prevailing food production, food processing and food trading practices" (G77 and China: 2004).

The significance of this intervention by the $\mathrm{G} 77$ and China was lost on many commentators. Yet, in a brief review of the final days of the consultation process, a reporter working for United Press International noted that WHO officials had launched a "diplomatic blitz" to save the global strategy whose fate rested "to a large extent, on the stance taken by the G77 group of developing countries" (John Zarocostas 28 April 2004). We highlight this report, in part, because it reveals the concerns that WHO had for the efficacy, and perhaps legitimacy, of the strategy. After all, it could not conceivably be referred to as a 'global' strategy is so many countries refused to sign up to it. However, more importantly, we believe that it is in such interventions that a sense of the post-colonial rather than the imperial emerges. Put differently, although the nations represented by G77 and China were, in King's (2002) terms, integrated into the strategy, they were in no way passive as regards their response(s) to it.

\section{Conclusion}

It has become increasingly apparent, particularly in the last decades of the twentieth century, that the inter-relationship between globalisation and health is extremely complex. The nature of this association is most evident in debates surrounding the re-emergence of infectious diseases, where it is recognised that the processes of globalisation have combined to create the conditions where once localised, microbial hazards have come to pose a threat to many western nations (Turner, 2003). However, in an emerging literature relating to the epidemic of non-communicable diseases, it is the so-called 'western lifestyle' that has been cast as the main threat to a population's health. As McMurray argues, globalisation impacts on the health of peripheral countries, that is the less- and least-developed countries, through its "promotion of particular [western] lifestyles and lifestyle habits that increase the risk of noncommunicable diseases" (2004: 100). The question that we raise in this paper is how we begin to investigate this development in global public health.

In order to answer this question, and by way of a conclusion, we point to two possibilities. Firstly, given our interest in debates relating to governance and the ethical management of the healthy body, our initial thoughts were to explore the possibility that we are witnessing the materialisation of an 'ethics of care' similar to that found in the West (Rose, 1999). As we have revealed in earlier work into the WHO global strategy (Brown and Bell, 2007), this is certainly a theoretical 
frame that is worth pursuing further. Moreover, it is one that allows us to consider critically the "hype and hope" that is embedded within the discourse of international organisations like $\mathrm{WHO}$, concerned as they are with managing individual conduct in ways that replicate the desires of the national bio-political state (Nerlich and Halliday, 2007). Yet, we need to take care when extending this form of analysis. As Brown and Duncan (2002) argue, there is a tendency within this literature to replicate Foucault's docile or passive body, one which is trapped in the ever-more powerful and disciplinary gaze of public health knowledge and practice. It would be a mistake to argue that non-western nations are similarly 'enframed'.

It is for this reason that in this paper we raised a second issue. That is, we pointed to the possibility that the WHO global strategy, when the subject of a more subtle reading, might be thought of in postcolonial terms. As we demonstrate, the strategy is driven by a desire to integrate 'developing' nations into a common narrative regarding the current and future condition of global health. Crucial to this process of integration is the evidence upon which the global strategy was built. Initially, this evidence, as set out in the $1990 \mathrm{WHO}$ Technical Series Report, suggested that McMurray's 'peripheral nations' might be able to avoid the threats to health posed by the 'western lifestyle' if they adopted measures to prevent the so-called risk transition taking place. Yet, by the time that the $2003 \mathrm{WHO} / \mathrm{FAO}$ report was published, it is apparent that, for those experts who produced it, this possibility had receded and that such nations needed to shift their focus from the prevention of lifestyle change to the management of the unhealthy body.

In some ways, this 'transition narrative', which in a reversing of the modernisation thesis encourages nations to learn from the negative experiences of the industrialised West, appears to re-assert what Slater and Bell (2002: 35) refer to as "colonial visions of tutelage". However, it is evident that many non-western nations sought to resist the seemingly imperial overtones of the global strategy. As we reveal, in their individual and collective responses, such nations emphasised their concerns regarding the western focus of the evidence underpinning the strategy, they highlighted their belief that the strategy needed to reflect their social and cultural differences from the industrialised West and they pointed to their rights as sovereign nations to manage their own public health priorities. This does not necessarily reflect a denial of the very real health-related issues that are raised by the global strategy but does suggest that, when interpreted as a complex process, the dynamic relations of power that exist between the countries of the West/non-West are exposed. 


\section{Bibliography}

Ali, S. H., \& Keil, R. (2006). Global cities and the spread of infectious disease: the case of severe acute respiratory syndrome (SARS) in Toronto, Canada. Urban Studies, 43, 491-509.

Bashford, A. (2006). Global biopolitics and the history of world health. History of the Human Sciences, 19, 67-88.

Bell, M. (2002). Inquiring minds and postcolonial devices: examining poverty at a distance. Annals of the Association of American Geographers, 92, 507-523.

Beaglehole, R., \& Yach, D. (2003). Globalisation and the prevention and control of non-communicable disease: the neglected chronic diseases of adults. The Lancet, 362, 903-908.

Brown, T., \& Bell, M. (2007). Off the couch and on the move: global public health and the medicalisation of nature. Social Science \& Medicine, 64, 1343-1354.

Brown, T., \& Duncan, C. (2002). Placing geographies of public health. Area, 33, 361-369.

Brown, T. M., Cueto, M., \& Fee, E. (2006). The World Health Organization and the transition from 'international' to 'global' health. In A. Bashford (Ed.), Medicine at the border: disease, globalization and security, 1850 to the present (pp. 7694). Basingstoke: Palgrave Macmillan.

Brundtland, G-H. (1998). Speech to the Fifty-first World Health Assembly Geneva, 13 May 1998. A51/DIV/6.

Carolina, M. S., \& Gustavo, L. F. (2003). Epidemiological transition: model or illusion? A look at the problem of health in Mexico. Social Science \& Medicine, $57,539-550$.

Chakrabarty, D. (1992). Postcoloniality and the artifice of history: who speaks for "Indian" pasts? Representations, 37, 1-26.

Coveney, J. (1998). The government and ethics of health promotion: the importance of Michel Foucault. Health Education Research, 13, 459-468.

Driver, F. (2004). Imagining the tropics: views and visions of the tropical world. Singapore Journal of Tropical Geography, 25, 1-17.

Foucault, M. (1977). Discipline and punish: the birth of the prison. London: Allen Lane. 
Foucault, M. (1979). The history of sexuality: volume 1, an introduction. London: Allen Lane.

Garrett, L. (1995). The coming plague: newly emerging diseases in a world out of balance. New York. Penguin Books.

Garrett, L. (1996). The return of infectious disease. Foreign Affairs, 75, 66-79.

G77 and China. (2004). Final communiqué: adopted by the thirty-sixth meeting of the chairmen/coordinators of the chapters of the Group of 77. Geneva, 9-11 March 2004 <http://www.g77.org/news/pr031104.htm> (accessed 25 June 2007).

Heymann, D. L., \& Rodier, G. R. (2001). Hot spots in a wired world: WHO surveillance of emerging and re-emerging infectious diseases. The Lancet Infectious Diseases, 1, 345-353.

King, N. B. (2002). Security, disease, commerce: ideologies of postcolonial global health. Social Studies of Science, 32, 767-68.

King, N. B. (2004). The scale politics of emerging infectious diseases. Osiris, 19, 62-76.

Loughlin, K., \& Berridge, V. (2002). Global health governance: historical dimensions of global governance Discussion Paper No.2. Centre on Global Change \& Health, London School of Hygiene \& Tropical Medicine/Department of Health \& Development, World Health Organization.

Lupton, D. (1995). The imperative of health: public health and the regulated body. London: Sage.

McEwan, C. (2003). Material geographies and postcolonialism. Singapore Journal of Tropical Geography, 24, 340-355.

McMichael, A. J., \& Beaglehole, R. (2000). The changing global context of public health. The Lancet, 356, 495-499.

McMurray, C. (2004). Globalization and health: the paradox of the periphery. Perspectives on Global Development and Technology, 3, 91-108.

Mills, S. (1997) Discourse. London: Routledge.

Nerlich, B., \& Halliday, C. (2007). Avian flu: the creation of expectations in the interplay between science and the media. Sociology of Health \& IIIness, 29, 4665. 
Omran, A. R. (1971). The epidemiologic transition: a theory of the epidemiology of population change. Milbank Memorial Fund Quarterly, 29, 509-538.

Petersen, A., \& Lupton, D. (1996). The new public health: health and self in the age of risk. London: Sage.

Pick, D. (1989). Faces of degeneration: a European disorder, c. 1848-1918. Cambridge: Cambridge University Press.

Porter, D. (2000). The Healthy Body in the Twentieth Century. In R. Cooter and J. Pickstone (Eds.), Medicine in the Twentieth Century (pp. 201-206).

Amsterdam: Harwood Academic Publications.

Rose, N. (1999). Powers of freedom: reframing political thought. Cambridge: Cambridge University Press.

Said, E. (1978). Orientalism: western conceptions of the Orient. London: Routledge \& Kegan Paul Ltd.

Said, E. (1983). The world, the text and the critic. Cambridge, Mass.: Harvard University Press.

Seale, C. (2000). Changing patterns of death and dying. Social Science \& Medicine, 51, 917-930.

Sidaway, J. D. (2000). Postcolonial geographies: an exploratory essay. Progress in Human Geography, 24, 591-612.

Siddiqi, J. (1995). World health and world politics. University of South Carolina Press: Columbus, South Carolina.

Slater, D. (1993). The geopolitical imaginations and the enframing of development theory. Transactions of the Institute of British Geographers, 18, 419-437.

Slater, D. (1998). Post-colonial questions for global times. Review of International Political Economy, 5, 647-678.

Slater, D. (2006). Imperial powers and democratic imaginations. Third World Quarterly, 27, 1369-1386.

Slater, D., \& Bell, M. (2002). Aid and the geopolitics of the post-colonial: critical reflections on New Labour's overseas development strategy. Development and Change, 33, 335-360. 
Turner, B. (2003). Social fluids: metaphors and meanings of society. Body \& Society, 9, 1-10.

USDHHS. (1996). Physical activity and health: a report of the Surgeon General. Centers for Disease Control and Prevention, National Center for Chronic Disease Prevention and Health Promotion, Atlanta.

WHO. (1966). Research in cardiovascular diseases. World Health Assembly, WHA19.38. Geneva: WHO.

WHO. (1972). Cardiovascular diseases. World Health Assembly, WHA25.44. Geneva: WHO.

WHO. (1976). Cardiovascular diseases. World Health Assembly, WHA29.49. Geneva: WHO.

WHO. (1985). Prevention and control of chronic noncommunicable diseases. World Health Assembly, WHA38.30. Geneva: WHO.

WHO. (1990). Diet, nutrition and the prevention of chronic diseases: Report of a WHO Study Group. World Technical Report Series 797. Geneva: WHO.

WHO. (1997). World health report, 1997: conquering suffering/enriching humanity. Geneva: WHO.

WHO. (1998). Noncommunicable disease prevention and control. World Health Assembly, WHA51.18. Geneva: WHO.

WHO. (2002). World health report, 2002: Reducing risks, promoting healthy life. Geneva: WHO.

WHO. (2003a). Consultation document to guide development of a WHO global strategy for diet, physical activity and health.

$<$ http://www.who.int/dietphysicalactivity/strategy/consult/index/en/> (accessed 25 June 2007)

WHO. (2003b). African regional consultation meeting report

<http://www.who.int/dietphysicalactivity/media/en/gscon_cs_report_afro.pdf> (accessed 25 June 2007)

WHO. (2004a). Global strategy on diet, physical activity and health. World Health Assembly, WHA 57.17. Geneva: WHO.

WHO. (2004b). Nutrition labels and health claims: the global regulatory environment. Geneva: WHO. 
WHO. (2004c). Comments from member states

<http://www.who.int/dietphysicalactivity/strategy/eb11344/en/index1.html>

(accessed 25 June 2007)

WHO. (2006). Reducing salt intake in populations. Geneva: WHO.

WHO. (2007a). A guide for population-based approaches to increasing levels of physical activity: implementation of the WHO global strategy on diet, physical activity and health. Geneva: WHO

WHO. (2007b). World Health Assembly Technical briefing: Country Experiences $<$ http://www.who.int/dietphysicalactivity/strategy/wha59briefings/en/> (accessed 25 June 2007)

WHO/FAO. (2003). Diet, nutrition and the prevention of chronic diseases: Report of a joint WHO/FAO expert consultation. World Technical Report Series 916.

Geneva: WHO.

Yach, D., \& Betcher, D. (1998). The globalization of public health, I: threats and opportunities. American Journal of Public Health, 91, 1745-8. 
1) The notion of a 'spatial genealogy' on page 2 needs more explanation.

Spatial has been removed and added brief explanation of reference to genealogy.

2) The 3rd para on page 2 is a little unclear. Please could you clarify whether the ideas of a colonial transition narrative is the ideas you propose to carry forward to the discussion in this paper?

Clarification has been added, notably that paper will focus on notion of transition narrative

3) Also in the 2nd para on page 3, could you confirm that you did mean to describe 'travel in one direction, from the non-west to the west' (and not vice versa?)

Agreed, sentence confusing so has been amended.

4) Before we get to the section on 'situating the global strategy' please could you add some discussion of your research strategy - the implication is that you made a reviwe of policy through SHO documents from the archive, so you might explain how these were sources, selected and analysed?

Two paragraphs added at bottom of page 3 to elaborate a little more explicitly on the research strategy.

5) p6 first line might read more precisely as ...'urban elite class in non-western countries, rather than...?

Amended as suggested

6) p7 please add a sentence toouline the argument put forward by Siddiqi (1995).

Otherwise this reference is a bit 'cryptic'.

Added points of clarification.

7) p8 3rd para should read something like: '...differences between the 1990 and 2003 reports..' to clarify the comparison being made here.

Amended as suggested.

8) p10 line 3 should read 'largely the same' in all parts of the world and line 6 would read better as 'However, if....'

Amended as suggested.

9) p11 It would be advisable to add a sentence or phrase explain what the G\&\& countries are?

Added sentence to explain significance of G77 
10) p13 you needed to establish the idea of 'global ethic of care' ealier and make much clearer why you refer to it here on $\mathrm{p} 13$.

Reference to 'global' removed and added reference to Brown and Bell 2007; text now makes sense in context to changes already made.

11) You lapse, around p13 to talking about north/south instead of western/nonwestern, which seems rather a non-sequitor. Could you check the way that you use these labels and explain them appropriately?

Checked and amended as suggested, paper now employs non-west/west rather than mixture of both. 